\title{
DIETETIC MANAGEMENT OF MALNUTRITION IN A HEALTHCARE SETTING: A SIX MONTH PRAGMATIC RANDOMISED CONTROLLED TRIAL WITH A 24 MONTH FOLLOW-UP
}

\author{
M. Milosavljevic ${ }^{1}$, S. Bowden ${ }^{1}$, A. Ferguson ${ }^{1}$, L. Barone ${ }^{1}$, S. Mason ${ }^{1}$, L. Tapsell ${ }^{2}$, G. Noble ${ }^{2}$
}

\begin{abstract}
Background: This study explored approaches to long term dietetic management of disease related malnutrition, a growing problem across hospitals in the industrialised world. Objectives: The aim of this study was to compare the effectiveness of two current models of dietetic care for patients with Disease Related Malnutrition. Design: A six month pragmatic randomised controlled trial was conducted with a 24 month follow up. Setting: All patients referred to the dietitian from two general medical and two surgical wards at a major public regional referral centre who met the inclusion criteria were invited to participate. This included being identified on admission as "at risk" of malnutrition or malnourished. Participants: Dietitians attended to 1222 patients during the recruitment period. From 320 eligible participants, 241 (78\%) were recruited; of these only 85 (27\%) completed the study. Intervention: It compared extended community-based dietetic management with the more traditional short-term hospital care alone. Measurements: A series of variables were recorded at enrolment, six months and then a follow up at 24 months. These included: nutritional assessment, level of satisfaction with the dietetic service, bed day utilisation, readmission and mortality rates. Results: An intention to treat analysis showed both groups had a significant improvement in nutritional status at six months and this was maintained at 24 months. When patients received an extended community care dietetic service they were significantly more satisfied with the dietetic service than those who did not receive the service $(\mathrm{P}<0.001)$. Conclusion: The current standard dietetic care of patients admitted to our institution led to significant improvements in their nutritional status at six months and two years from initial contact. The patient's level of satisfaction with the dietetic service was high when they were seen in the community.
\end{abstract}

Key words: Disease related malnutrition, dietetic management, patient satisfaction, models of care.

\section{Introduction}

Disease related malnutrition (DRM) is now an accepted and growing problem across hospitals in the industrialised world (1,2), including Australia (3, 4). From the poorly acknowledged reality to a wellrecognised problem, DRM has slowly gained both recognition and status. The majority of research on this subject has been on the identification and prevalence $(5,6)$, and to a lesser extent, treatment of the condition $(5,7)$. A review found that nutritional supplementation is an effective intervention (8) but there is still a lack of convincing evidence demonstrating the effectiveness of dietary counseling/advice in the treatment of DRM

1. Illawarra Shoalhaven Local Health District; 2. University of Wollongong, Australia

Corresponding Author: Marianna Milosavljevic, Illawarra Shoalhaven Local Health District, Research Office, Locked Mail Bag 8808, South Coast Mail Centre, NSW, 2521, Australia, Phone (02) 4253 4875, Fax (02) 4253 4803, Email: Marianna.milosavljevic@health.nsw.gov.au

Received May 24, 2016

Accepted for publication June 28, 2016
(9). Since these reviews there have been a number of randomised controlled trials (RCTs) assessing the effectiveness of dietetic counselling for the treatment of malnutrition. An Israeli study on hospitalised patients found, over a six month period, the group receiving dietetic counselling had a significant improvement in nutritional status and a reduced mortality rate when compared to the groups that did not receive dietetic care after leaving hospital (10). A Danish study on elderly patients admitted to a geriatric ward compared dietetic follow-up after hospital discharge versus routine GP care. This study found significant improvement in the group receiving dietetic care in nutritional and functional status after 12 weeks of intervention (11). Another Danish trial examined elderly rehabilitation patients and found that having a dietitian within the discharge care team improved nutritional status and reduced the number of readmissions to hospital in a six month period (12). A Dutch study examined elderly patients in a community setting and found dietetic counselling did not improve 
outcomes compared to standard treatment (13). All these trials used strict eligibility criteria, were conducted over relatively short time periods, used treatment regimens not always feasible in the clinical setting and were conducted in countries other than Australia. Therefore, we felt a study that assessed standard dietetic practices, within an Australian public hospital, may assist dietitians to identify the most effective model of care for the type of patients referred to their services.

The aim of this study was to compare the effectiveness of two current models of dietetic care for patients "at risk" of malnutrition or already malnourished, within the Australian public hospital system. This study was called the Community Outpatient Management of Malnutrition Incorporating Individualised Therapy (COMMIIT) trial.

\section{Methods}

\section{Study Design}

This was a six month pragmatic RCT, with a 24 month follow-up. It compared extended community-based dietetic management with the more traditional shortterm hospital care alone. The study design followed the guidelines outlined in the CONSORT 2010 Statement and was registered at the Australian New Zealand Clinical Trials Registry (anzctr.org.au: ACTRN12611000851965). Figure 1 provides a schematic representation of the study protocol.

Figure 1

Schematic representation of the study protocol

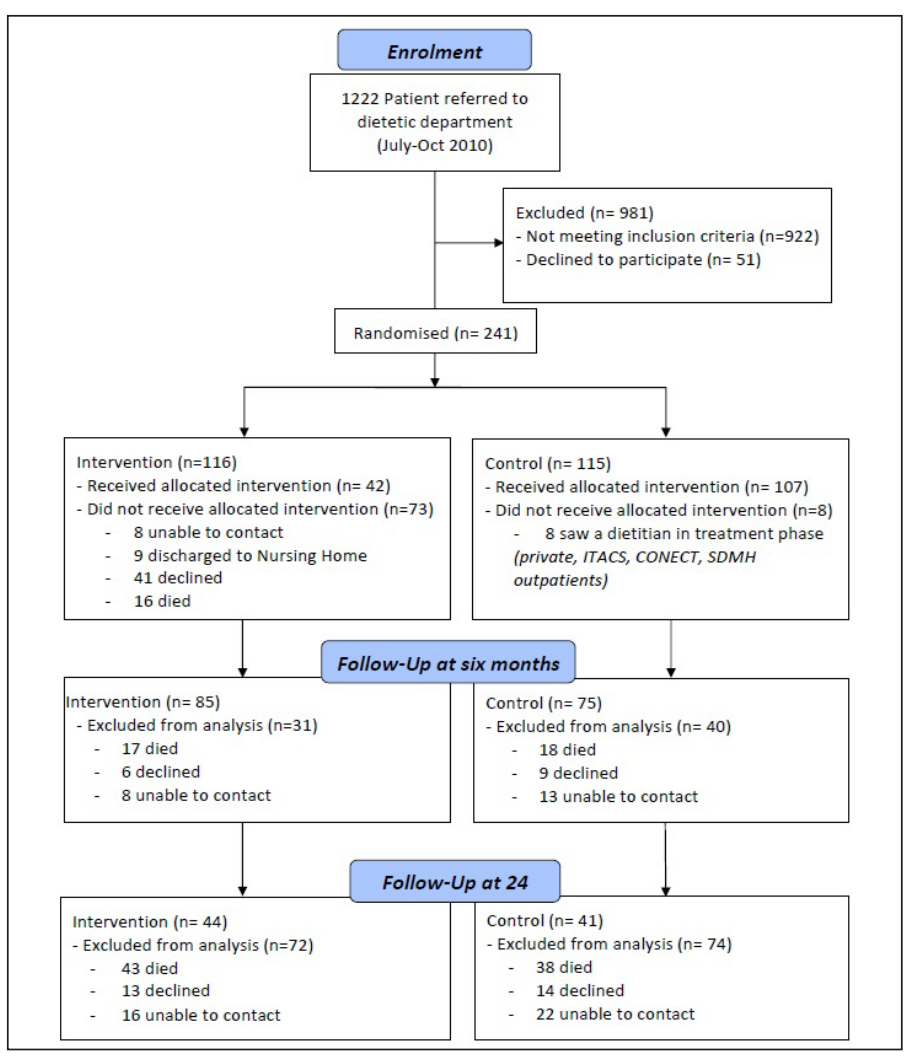

\section{Patient Selection and Setting}

All patients referred to the dietitian from the two general medical and two surgical wards at a major public regional referral centre from July to October, 2010 who and met the inclusion criteria as follows: identified on admission as "at risk" of malnutrition or malnourished; over 18 years of age; not palliative; expected to return to their home after discharge; and assessed as requiring on-going dietetic care after discharge. There were a small number of patients assessed as wellnourished but considered by the admitting dietitian to be in deteriorating health, who were also included. An interpreter service was available for non-English speaking participants. Verbal informed consent was received.

\section{Treatment Groups}

The control and intervention groups both received the same dietetic management throughout their hospital admission. This involved each patient being assessed by a dietitian and provided with a customised nutrition care plan during their hospital stay. This plan identified their short and long term nutritional goals such as an increase in energy intake, identification of any nutritional issues and required dietary changes. Prior to discharge both groups received an education session covering their dietetic care plan (up to 30 minutes duration). In addition to this education session the intervention group was given a follow-up appointment with the community-based dietitians whilst the control group was only provided with a contact number of the dietetic department.

\section{Outcome Measures}

The primary outcome measures were mortality and readmission rates, as well as, total bed days occupied. The secondary outcome measures were the change in nutritional status and patient level of satisfaction with the service provided.

\section{Randomisation Process}

This study followed a stratified randomisation process in that the patients with chronic airways limitations were randomised separately to ensure even distribution across the groups. Sealed opaque envelopes that each contained a random number were prepared prior to the commencement of the study period. A second separate random number generated list was created for those patients identified with a chronic airways limitation disease as per stratification randomisation procedure. A staff member, not involved directly in the study was assigned the role of allocation officer. Their task was to allocate consented patients on a daily basis. They 
also kept a record of patient details and assigned group allocation in the study database.

\section{Recruitment Process}

On admission all patients referred to the dietetic department were assessed by the dietitian providing the service to that ward. If they met the eligibility criteria they were invited to participate in the study. If they agreed to participate they were randomised to either the control or intervention group. The following patient data were collected: age, gender, level of education, partner status, nutritional assessment, primary diagnosis, length of hospital stay, discharge destination.

At six months all patients enrolled in the study were contacted by the research dietitian to measure their current nutritional status and level of satisfaction with the service. At 24 months patients were contacted and if possible all parameters were re-measured, except for the patient satisfaction survey.

\section{Tools Used}

Nutritional status was assessed by the hospital dietitians who were trained in using validated nutritional assessment tools; either the Mini nutritional assessment (MNA) if 65 years or older (14), Subjective Global Assessment (SGA) if under 65 years of age (15). Patient weights were recorded using the hospital ward scales (to the nearest $0.1 \mathrm{~kg}$ ) and height was estimated using self-reported heights from the patient or family/carers. A portable electronic scale was used for all weights measured outside the hospital-Tanita scale HD-316.

Patient Perspective Assessment- A validated outpatient patient dietetic satisfaction survey was administered at six months (16). This survey tool measured five aspects (domains) of the dietetic care received by the patient and these were: staff presentation, interpersonal skill, perceived health benefit, written information and overall expectations.

\section{Ethics}

Ethics was approved by the local area health service and university ethics committee. The project met the guidelines of the responsible government agency.

\section{Statistical Analysis}

All statistical analyses were performed using Microsoft Excel Add In version 7. Primary analysis was undertaken using intention-to-treat principles (itt). Wilcoxon signed rank test, Mann-Whitney U-test, chi-square and fishers exact tests of associ $\neg$ ations were used as appropriate. Data are presented as mean $( \pm S D)$, number $(\%)$. A p-value $<0.05$ was considered significant.

\section{Results}

Dietitians attended to 1222 patients during the recruitment period. Of this number 320 were eligible to participate and 241 patients $(78 \%)$ accepted. There was no difference between the participants and non-participants in relation to age, sex and admission diagnosis, except for chronic airways limitations. Table 1 describes the baseline characteristics of the participants.

Table 1

Baseline characteristics of study participants

\begin{tabular}{|c|c|c|c|}
\hline Characteristics & $\begin{array}{c}\text { Control } \\
(n=115)\end{array}$ & $\begin{array}{l}\text { Intervention } \\
\quad(n=116)\end{array}$ & p value \\
\hline & \multicolumn{3}{|c|}{ Mean (SD) } \\
\hline Age (years) & $75.3( \pm 14.1)$ & $74.8( \pm 13.5)$ & .776 \\
\hline Body weight (kg) & $66.4( \pm 17.7)$ & $63.7( \pm 15.3)$ & .225 \\
\hline \multirow[t]{2}{*}{ Length of hospital stay (days) } & $27.2( \pm 36.4)$ & $22.9( \pm 24.2)$ & .294 \\
\hline & \multicolumn{3}{|c|}{ Frequencies $(\%)$} \\
\hline \multicolumn{4}{|l|}{ Gender: } \\
\hline Male & $56(48.70)$ & $55(47.41)$ & .845 \\
\hline Female & $59(51.30)$ & $61(52.59)$ & \\
\hline Living without support & 45 (39.13) & $43(37.07)$ & .747 \\
\hline Independent in mobility & $99(86.09)$ & $92(79.31)$ & .174 \\
\hline Diabetes mellitus & $19(16.52)$ & $16(13.79)$ & .400 \\
\hline Renal disease & $4(3.48)$ & $6(5.17)$ & .748 \\
\hline Respiratory disorders & $20(17.39)$ & $11(9.48)$ & $<.001$ \\
\hline Neurological disorders & $20(17.39)$ & $23(19.82)$ & .634 \\
\hline Reduced mobility conditions & $28(24.34)$ & $25(21.55)$ & .613 \\
\hline \multicolumn{4}{|l|}{ Nutritional Status on admission: } \\
\hline Well nourished & $10(8.77)$ & $13(11.20)$ & .812 \\
\hline At risk & $73(64.04)$ & $71(61.21)$ & \\
\hline Malnourished & $31(27.19)$ & $32(27.59)$ & \\
\hline
\end{tabular}

A number of the intervention group participants who initially agreed to be followed up after leaving hospital then changed their mind once back at home. This resulted in 43 participants in the intervention group not being seen by the dietitian (i.e. $50 \%$ of the intervention group did not receive the treatment). The result of this non-acceptance was that only 42 participants were seen by the dietitian in the community. The intervention group received on average 2.6 dietetic consultations versus 0.8 visits in the control group. Outcome measures observed at the six month and 24 month follow up can be seen in Table 2. Changes in nutritional status at baseline, six and 24 months can be seen in Figure 2.

Results from the patient satisfaction survey highlighted that the intervention group had higher levels of satisfaction with the dietetic service in all four domains except one, which was 'perceived benefits of the services'. Results from the survey can be seen in Table 3. 
Figure 2

Nutritional status at baseline, six and 24 months

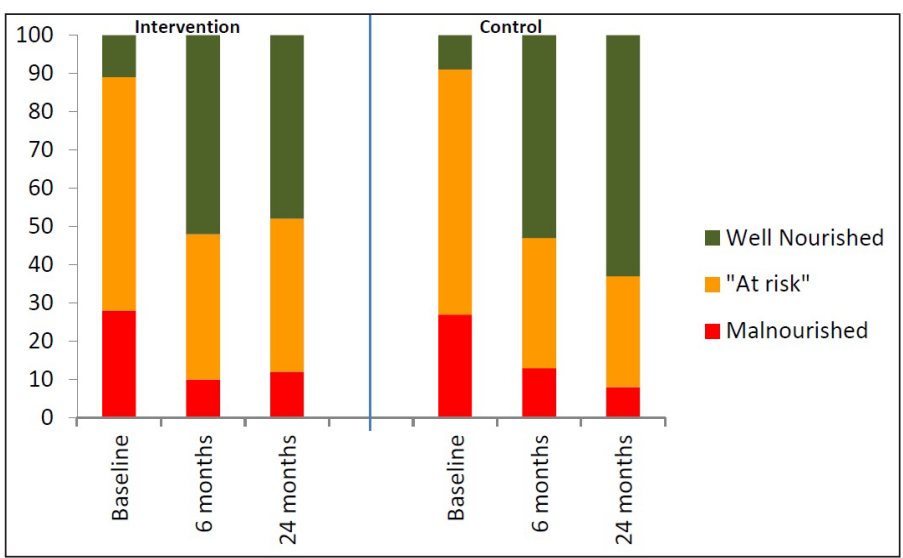

Table 2

Comparison of changes in clinical features at 6 and 24 month follow up periods

\begin{tabular}{|c|c|c|c|}
\hline \multicolumn{4}{|c|}{ Changes at 6 Months } \\
\hline Parameters & $\begin{array}{c}\text { Control } \\
(n=75)\end{array}$ & $\begin{array}{l}\text { Intention to } \\
\text { treat }(n=85)\end{array}$ & p value \\
\hline Percentage BMI Change (mean) & -0.42 & -0.46 & 0.548 \\
\hline Percentage Weight Change (mean) & -0.22 & -0.06 & 0.864 \\
\hline Re-admission rate (mean) & 4.8 & 5.1 & 0.731 \\
\hline Hospital bed days (mean) & 58.5 & 61.6 & 0.923 \\
\hline Mortality (n) & 18 & 17 & 0.570 \\
\hline Drop out (n) & 22 & 14 & 0.151 \\
\hline \multicolumn{4}{|c|}{ Changes at 24 Months } \\
\hline Parameters & $\begin{array}{c}\text { Control } \\
(n=41)\end{array}$ & $\begin{array}{l}\text { Intention to } \\
\text { treat }(n=44)\end{array}$ & p value \\
\hline Percentage weight change (mean) & 2.9 & 2.1 & 0.654 \\
\hline Re-admission rate (mean) & 8.9 & 9.6 & 0.898 \\
\hline Mortality (n) & 38 & 43 & 1 \\
\hline Drop Out (n) & 36 & 29 & .079 \\
\hline
\end{tabular}

Table 3

Level of Satisfaction with the Dietetic Service at 6 months as measured by number of agreed and strongly agreed category responses

\begin{tabular}{|c|c|c|c|}
\hline Domain & $\begin{array}{c}\text { Control } \\
(\mathrm{n}=41)\end{array}$ & $\begin{array}{l}\text { Intervention } \\
\quad(\mathrm{n}=57)\end{array}$ & p value \\
\hline & \multicolumn{3}{|c|}{ Agree and strongly agree responses $(\%)$} \\
\hline $\begin{array}{l}\text { Interpersonal \& Staff } \\
\text { Presentation Skills }\end{array}$ & 70.7 & 94.1 & $<0.001$ \\
\hline Perceived Health Benefits & 49.1 & 58.6 & 0.562 \\
\hline Written Materials & 20.5 & 38.0 & $<0.001$ \\
\hline Fulfilled Expectations & 27.9 & 43.7 & $<0.001$ \\
\hline
\end{tabular}

\section{Discussion}

This is the first long-term, pragmatic RCT that compared two existing models of dietetic management for patients identified as at risk or malnourished in an Australian public hospital. This study found both groups (inpatient dietetic service and community follow-up) had significant improvements in nutritional status at six months. This was maintained for two years after initial contact. There were no differences observed between the groups in the number of: hospital admissions, occupied bed days and mortality rates. The only difference found was in the level of patient satisfaction. Those patients who received the community follow up were far more satisfied with the dietetic service than those who received standard hospital care. This study also illustrated the challenges encountered when conducting a pragmatic RCT including: the large drop-out rate despite high initial rates of agreement to participate, maintaining contact with patients after discharge, the ethical considerations regarding availability of a service, the patients' perceived usefulness of a dietetic intervention after leaving hospital, the use of validated assessment tools in a more heterogeneous patient population, and the practical realities of the type of service that can be offered within a clinical setting.

We found that most patients agreed to participate when approached by the dietitian (78\%). However, once they returned home, many simply changed their minds. There was a $30 \%$ dropout rate at six months, half of that was due to death and the rest was due to inability to contact the patients or they had changed their minds about being involved in the study. By the two year follow-up there was a $60 \%$ dropout rate (one third to death and two-thirds due to inability to contact or refusal to participate). These dropout rates mean, there was a serious threat to the validity of the study, as less than a $20 \%$ drop out is considered to be the difference between a "high" and "low" quality randomised trial (17).

The patient satisfaction survey that showed dietetic involvement in the community was viewed favorably by the patients receiving that service. This is an important finding as a patient's view of the care provided is as a vital component of the provision of healthcare. A review article on the patient satisfaction literature described patient satisfaction as an indicator that "represents a useful complement to other indicators: easily monitored and capable of integrating individuals and populations into the decision-making process in the health sector" (18). We found the intervention group had far higher levels of satisfaction with the dietetic service in all domains, except one. That notable exception was the domain that focused on 'perceived benefits of the services'. In this domain there was no difference between the groups and only half of all the respondents agreed with that statement. This may suggest that many of the patients in both arms of the study did not see 
how nutrition was connected to their health status. We postulate this may explain in part why so many participants initially agreed to seeing the dietitian, but upon returning home felt the service was not required. The failure of patients to attend appointments has been explored within the diabetes population. A systematic review of attrition from diabetes education services found there were many factors associated with attrition including psychosocial and contextual variables such as patient's perceived value of the service or the level of their health locus of control (19). This does raise the questions "how well do patients understand the link between nutrition and malnutrition and do they think nutrition is important?"

The strength of the COMMIIT trial is that it was a pragmatic RCT as opposed to an explanatory one. Whereas an explanatory RCT aims to evaluate the efficacy of an intervention in a well-defined and controlled setting, the pragmatic RCT is used to test the effectiveness of the intervention in a broad routine clinical practice (20). Although the pragmatic nature of this study also provided additional insight into dietetic models of care, it also presented many challenges. Despite the issues, it is this very type of trial that can assist clinicians in developing the most viable and realistic methods of treatment for their patients. A pragmatic RCT represents a compromise between observational studies, which have good external validity at the expense of internal validity, and conventional (explanatory) RCTs, which have good internal validity at the expense of external validity (21). One of the criticisms of the explanatory RCT design is the fact that many are not transferable to the "real clinical world". These criticisms are levelled as they usually have strict patient eligibility criteria, and a level of intervention provided that is not always economically realistic (22). This trial was conducted within a clinical setting and included a heterogeneous range of patient groups. It showed that patients identified as malnourished or "at risk" of malnutrition improved at the same rate, with or without planned after-hospital dietetic care. However, due to ethical considerations all patients in the study did have access to after-hospital dietetic care and, according to the findings of this study; this appeared to be adequate in terms of showing an improvement in the overall nutritional status. However, there was only a small difference in the number of dietetic visits between the two groups: 2.6 versus 0.8 . This would suggest the existing systems are adequate to facilitate an improvement in health in this population examined. The intervention may work better with more carefully diagnosed patients, or those better selected in terms of disease severity, or in those with less co-morbidities or better compliance, or with closer monitoring, or in settings with a higher commitment to and/or more experience with the intervention (22).

Another possible explanation for our findings could be the specificity of the MNA tool in this clinical setting. If the specificity was low it would mean we may have included many false positives, that is patients identified as at risk of malnutrition that may not have been at risk. Within the literature the MNA tool has been reported as having specificity scores ranging from 36\% to $100 \%$ depending on the clinical setting (23). There have been two similar studies citing MNA specificity scores of $36 \%$ and $37-50 \%$. These studies were on elderly women with rheumatoid arthritis in a medical ward (24) and elderly orthopedic women in a surgical ward (25). Interestingly, the latter study found the specificity was much lower for the "at risk" of malnutrition then the malnourished category. Within our trial the majority of patients were identified as "at risk" of malnutrition (approximately $60 \%$ ). Therefore, some of this group may have improved regardless of the intervention as they were not really at risk.

We found the intervention and control groups both showed a significant improvement in nutritional status at six months, but no difference in clinical outcomes. These findings are consistent with the systematic review that showed dietary counselling improved nutritional indices but did not have any clinical benefits (9). This does differ from individual studies that found intensive after-hospital care with dietetic or nutrition intervention in a select patient group can improve nutritional status and in some cases reduce mortality (10-12). However, these studies had different selection processes such as randomised patients based on ward location and month of the year (10), they used homogenous patient groups such as frail elderly (12) or oncology patients (26), or included supplements as part of their dietetic intervention (11). Whereas, when a study did use a similar intervention as in our study and in a more heterogeneous group of elderly patients, they too were unable to find differences in nutrition outcomes (13). This does suggest the effectiveness of the intervention is specific to different patient groups; therefore, dietetic intervention may be better targeted at those groups most likely to respond well to the treatment.

We had a very high drop-out rate due to attrition, but patient dietary non-adherence has been citied from 30 to $80 \%$ depending on the type of intervention offered (27). Therefore it is not surprising this study found the dropout rate high. There is an argument that dropout rates are an important inclusion in that if an intervention is not wellaccepted then the overall usefulness of the intervention can be questioned. The provision of extended community dietetic care appears intuitive, but this trial did not show a difference in the outcomes measured. However, given the assessment tool used and number of possible false positives included it may require larger numbers to show a difference. One of the issues is this trial is the deliberate choice of a broader heterogeneous group, but this also meant that there may have been patients included who would have improved on their own, despite their initial assessment of "at risk" or malnourished.

This study did not find a significant difference in mortality rates or hospital readmission or bed utilisation 
days between the two groups. There was, however, a difference in bed utilisation days using a per protocol analysis. Care is required in drawing any conclusion from that analysis, as the dropout rate was high and those that were no longer in the intervention arm may have been admitted to another health district or higher care facilities.

\section{Limitations}

There are a number of limitations: the absence of a true control; it was conducted within a single site and in general medical and surgical wards only; it involved a small number of dietitians (seven in total); and it only measured surrogate markers of nutritional status (28).

\section{Conclusion}

This study showed the current standard of dietetic care led to significant improvements in patients' nutritional status at six months and two years from initial contact. It also highlighted the need for further research that explores the possible factors contributing to the high attrition rates amongst this patient population; it suggests the need for a more targeted delivery of dietetic services aimed at those patient groups more likely to benefit from limited resources and does raise the question around the specificity of the MNA tool in the general hospital population.

Funding: No sponsorship funding was received and therefore had no role in the design and conduct of the study, in the collection, analysis, and interpretation of data; in the preparation of the manuscript; or in the review or approval of the manuscript.

Acknowledgements: We would like to thank all the staff from the dietetic department who assisted in the study. Also we thank Janaye Fish and Jay Borchard who reviewed the manuscript and provided editorial assistance.

Conflict of interest: All the authors in this study declare neither financial nor non-financial competing interests.

Ethical standards: This study was approved by the University of Wollongong and Illawarra Shoalhaven Local Health District Human Research Ethics Committee and complied with current laws governing ethics in research.

\section{References}

1. Correia MI, Hegazi RA, Higashiguchi T, et al. Evidence-based recommendations for addressing malnutrition in health care: An updated strategy from the feedM.E. Global Study Group. JAMDA 2014 Aug;15(8):54450 .

2. Norman K, Pichard C, Lochs H, Pirlich M. Prognostic impact of diseaserelated malnutrition. Clin Nutr 2008;27(1):5-15.

3. Walton KL. Treating malnutrition in hospitals: Dietitians in the driving seat? Nutrition \& Dietetics 2009 Dec;66(4):202-5.

4. Charlton KE, Nichols C, Bowden S, et al. Older rehabilitation patients are at higher risk of malnutrition: evidence from a large Australian database. J Nutr Health Aging 2010 Oct;14(8)622-8.

5. White JV, Guenter P, Jensen G, et al. Consensus statement of the Academy of Nutrition and Dietetics / American Society for Parenteral and Enteral Nutrition: characteristics recommended for the identification and documentation of adult malnutrition (undernutrition). J Acad Nutr Diet 2012 May;112(5):730-8.

6. Barker LA, Gout BS, Crowe TC. Hospital malnutrition: prevalence, identification and impact on patients and the healthcare system. Int J Environ Res Public Health 2011 Feb;8(2):514-27.

7. Collins J, Porter J. The effect of interventions to prevent and treat malnutrition in patients admitted for rehabilitation: a systematic review with metaanalysis. J Hum Nutr Diet 2015 Feb;28(1):1-15.

8. Cawood AL, Elia M, Stratton RJ. Systematic review and meta-analysis of the effects of high protein oral nutrition supplements. Ageing Res Rev 2012 Apr;11(2):278-96.

9. Baldwin C, Weekes CE. Dietary advice with or without oral nutritional supplements for disease-related malnutrition in adults. Cochrane Database of Systematic Reviews. 2011. http:// onlinelibrary.wiley.com/ doi/10.1002/14651858.CD002008.pub4/pdf. Accessed 7 August 2015.

10. Feldlum I, German L, Castel H, Harman-Boehm I, Shahar Dr. Individualized nutritional intervention during and after hospitalization: the nutrition intervention study clinical trial. J Am Geriatr Soc 2011 Jan;59(11):10-17.

11. Beck AM, Kjær S, Hansen BS, Storm RL, Thal-Jantzen K, Bitz C. Followup home visits with registered dietitians have a positive effect on the functional and nutritional status of geriatric medical patients after discharge: a randomized controlled trial. Clin Rehabil 2013 Jun;27(6):483-93.

12. Beck A, Andersen U, Leedo E, et al. Does adding a dietician to the liaison team after discharge of geriatric patients improve nutritional outcome: A randomised controlled trial. Clin Rehabil. 2014. http://www.ncbi.nlm.nih. gov/pubmed. Accessed 7 August 2015.

13. Schilp J, Kruizenga HM, Wijnhoven HA, van Binsbergen JJ, Visser M. Effects of a dietetic treatment in older, undernourished, community-dwelling individuals in primary care: a randomized controlled trial. Eur J Nutr 2013 Dec;52(8):1939-48.

14. Guigoz Y, Vellas B, Garry PJ. The mini nutritional assessment: MNA. Nutrition in the elderly. 2007. Serdi Publishing Company, France.

15. Detsky AS, McLaughlin JR, Baker JP, et al. What is subjective global assessment of nutritional status? JPEN J Parenter Enteral Nutr 1987 JanFeb;11(1):8-13.

16. Vivanti A, Ash $\mathrm{S}$, Hulcombe J. Validation of a satisfaction survey for rural and urban outpatient dietetic services. J Hum Nut Diet 2007 Feb;20(1):41-9.

17. Fewtrell MS, Kennedy K, Singhal A, et al. How much loss to follow-up is acceptable in long-term randomised trials and prospective studies?. Arch Dis Child 2008 Jun;93(6):458-61.

18. Mpinga EK, Chastonay P. Satisfaction of patients: A right to health indicator? Health Policy 2011 May;100 (2-3) :144-50.

19. Gucciardi E. A Systematic Review of Attrition from Diabetes Education Services: Strategies to Improve Attrition and Retention Research. Can Diabetes 2008;32(1):53-65.

20. Patsopoulos NA. A pragmatic view on pragmatic trials. Dialogues Clin Neurosci 2011 Jun;13(2): 217-24.

21. Hotopf M. The pragmatic randomised controlled trial. Advances in Psychiatric Treatment 2002 Sep; 8(5):326-333.

22. Kent DM, Kitsios G. Against pragmatism: on efficacy, effectiveness and the real world. Trials 2009;10(1):48.

23. Secher M, Soto ME, Villars H, van Kan GA, Vellas B. The Mini Nutritional Assessment (MNA) after 20 years of research and clinical practice. Rev Clin Gerontol 2007;17:293-310.

24. Elkan AC, Engvall IL, Tengstrand B, Cederholm T, Hafstrom I. Malnutrition in women with rheumatoid arthritis is not revealed by clinical anthropometrical measurements or nutritional evaluation tools. Eur J Clin Nutr 2008 Oct;62(10):1239-47.

25. Murphy MC, Brooks CN, New SA, Lumbers ML. The use of the MiniNutritional Assessment (MNA) tool in elderly orthopaedic patients. Eur J Clin Nutr 2000 Jul;54(7):555-62.

26. Norman K, Kirchner H, Freudenreich M, Ockenga J, Lochs H, Pilrich M. Three month intervention with protein and energy rich supplements improve muscle function and quality of life in malnourished patients with nonneoplastic gastrointestinal disease - a randomized controlled trial. Clin Nutr 2008 Feb;27(1):48-56

27. Jin J, Sklar GE, Min Sen Oh V, Chuen Li S. Factors affecting therapeutic compliance: A review from the patient's perspective. Ther Clin Risk Manag 2008 Feb;4(1): 269-286.

28. Koretz RL, Avenell A, Lipman TO, Braunschweig CL, Milne AC. Does entera nutrition affect clinical outcome? A systematic review of the randomized trials. Am J Gastroenterol 2007 Feb; 102(2):412-29. 